\title{
Circulating stem cells, HIF-1, and SDF-1 in septic abdominal surgical patients: randomized controlled study protocol
}

Antonella Cotoia* (D), Lucia Mirabella, Sabrina Altamura, Rachele Villani, Flavia Marchese, Giuseppe Ferrara, Karim Mariano, Tullo Livio and Gilda Cinnella

\begin{abstract}
Background: Sepsis caused by complicated intra-abdominal infection is associated with high mortality. Loss of endothelial barrier integrity, inflammation, and impaired cellular oxygen have been shown to be primary contributors to sepsis. To date, little is known regarding the pathway for the mobilization of endothelial progenitor cells (EPCs) from the bone marrow in sepsis whereas stromal-cell-derived factor 1a (SDF-1a) and hypoxia inducible factor 1 (HIF-1) seem to have a role in the EPC response to hypoxic microenvironments.

The aims of the study are: (a) to determine the time course of the levels of circulating EPCs (CD133/CD34), SDF-1a, and HIF-1 in septic patients undergoing major abdominal surgery (group S), (b) to investigate the relationship between CD133/CD34, HIF-1, and SDF-1a, and (c) to investigate the relationship of these factors with the outcome of group S patients treated with standard conventional therapy alone $(C T)$ or with the addition of extracorporeal hemoperfusion therapy $(\mathrm{HCT})$.
\end{abstract}

Methods/design: Patients undergoing major abdominal surgery will be allocated into groups: postoperative nonseptic patients in an emergency surgical ward (group C) and postoperative septic patients in an intensive care unit (group S). The latter will be randomized to receive CT alone (S1) or with HCT (S2). Healthy volunteers (group H) will be recruited at University Hospital Foggia.

Peripheral blood (PB) samples will be collected preoperatively (T0), at $24 \mathrm{~h}(\mathrm{~T} 1), 72 \mathrm{~h}$ (T2), 7 (T3), and 10 (T4) postoperative days in groups $\mathrm{S}$ and $\mathrm{C}$, and at T0 in group H. The CD34/133 cells and HIF-1 counts will be determined by flow cytometer analysis. The concentration of SDF-1a in plasma will be calculated by enzyme-linked immunosorbent assay analysis (ELISA).

Discussion: This prospective randomized clinical trial is designed to investigate circulating stem cells, levels of HIF-1 and SDF-1a, and their interrelationship in septic postoperative abdominal surgical patients treated with $C T$ alone or with $H C T$. The rationale is that an integrated understanding of the role of hypoxia-related factors and EPCs in PB of septic patients could indicate which molecular processes need to be regulated to recover the innate immunity homeostasis. Understanding the function of EPCs in sepsis may provide innovative diagnostic and therapeutic approaches to improve the prognosis of this syndrome.

Trial registration: ClinicalTrials.gov: NCT02589535. Registered on 28 October 2015.

Keywords: Stem cells, Major abdominal surgery, Sepsis, Septic shock, Stromal cell-derived factor 1a, Hypoxia inducible factor 1

* Correspondence: antonella.cotoia@unifg.it

Department of Anesthesia, Intensive Care and Pain Therapy, University of

Foggia, University Hospital Foggia, Foggia, Italy

(c) The Author(s). 2018 Open Access This article is distributed under the terms of the Creative Commons Attribution 4.0 International License (http://creativecommons.org/licenses/by/4.0/), which permits unrestricted use, distribution, and reproduction in any medium, provided you give appropriate credit to the original author(s) and the source, provide a link to the Creative Commons license, and indicate if changes were made. The Creative Commons Public Domain Dedication waiver (http://creativecommons.org/publicdomain/zero/1.0/) applies to the data made available in this article, unless otherwise stated. 


\section{Background}

Complicated intra-abdominal infection is a frequent cause of sepsis and septic shock in intensive care unit (ICU) patients [1, 2]. Sepsis caused by intra-abdominal infection is associated with higher mortality ranging on average $30 \%$ to $60 \%$ because of (a) the broad spectrum of infection and disease severity, (b) the crucial role of surgery in the management of intra-abdominal infection, and (c) the ongoing emergence of multidrug resistance in pathogenic organisms [3-6].

Evidence supports that the pathophysiology of sepsis moves from an initiating early/acute hyperinflammatory phase to a late/chronic hypoinflammatory and immunosuppressive phase [7]. More recently, loss of endothelial barrier integrity, inflammation, and impaired cellular oxygen have been shown to be primary contributors to sepsis-related organ dysfunction [8]. Endothelial progenitor cells (EPCs), a specific subtype of hematopoietic stem cell, are mobilized into the peripheral circulation under various pathologic conditions that are associated with vascular injury [9-14]. Mutunga et al. observed an increase of circulating endothelial cells during sepsis and concluded that endothelial damage occurs [9]. However, the quantification of EPCs in septic patients has had controversial results and Cribbs et al. demonstrated that the increased levels of EPCs were inversely associated with organ dysfunction [15]. To date, little is known regarding the relationship between EPC and organ dysfunction in septic postoperative abdominal surgical patients.

In addition, the pathway for the mobilization of EPCs from the bone marrow (BM) in sepsis or septic shock is still unknown. Emerging evidence suggests that stromalcell-derived factor 1a (SDF-1a) mediates the migration of hematopoietic stem cells from BM to peripheral blood (PB), while hypoxia inducible factor 1 (HIF-1), which regulates SDF-1a expression, is the central mediator of the cellular response to hypoxic microenvironments [16].

\section{Aims of the study}

Primary objective: To determine the time course of the levels of circulating EPCs (CD133/CD34), SDF-1a, and HIF1 in septic patients undergoing major abdominal surgery.

Secondary objective 1: To investigate the relationship between CD133/CD34, HIF-1, and SDF-1a.

Secondary objective 2: To investigate the relationship between CD133/CD34, HIF-1, SDF-1a, and the outcome of sepsis and septic shock patients treated with standard conventional therapy alone $(\mathrm{CT})$ or with the addition of extracorporeal hemoperfusion therapy (HCT).

In this trial, we hypothesize that levels of CD133/CD34, HIF-1, and SDF-1a will increase in septic surgical patients as a consequence of impaired tissue perfusion and cellular hypoxia. Our hypothesis is that the stimulation of hypoxiarelated factors, like SDF-1a and HIF-1, could be the primary step in the stimulation of BM stem cells. Furthermore, we assume that surviving septic patients will show higher levels of EPCs, HIF-1, and SDF-1a.

\section{Methods/design}

\section{Recruitment}

This prospective observational clinical trial is designed to target postoperative patients undergoing major abdominal surgery and healthy volunteers at University Hospital Foggia. Participants who meet pre-specified eligibility criteria (Table 1) and provide written informed consent will be enrolled in the study.

Detailed information on the benefits and risks of taking a blood sample will be provided to study candidates. Human blood samples and therapies will be acquired in accordance with institutional guidelines. All patients will be managed by applying standard protocols, following current guidelines and recommendations. The diagnosis of sepsis and septic shock will be made according to the new definitions [17].

This study is to be performed in accordance with the World Medical Association Declaration of Helsinki: Ethical principles for medical research involving human subjects (WMA 20 2013) [18], the International Ethical Guidelines for Biomedical Research involving Human Subjects (CIOMS 2002) [19], and the ICH Harmonised Tripartite Guideline: Guideline for good clinical practice (ICH 1996) [20].

The study has been approved by the local research ethics committee (Comitato Etico of Ospedali Riuniti, Foggia, Italy, 69/CE/2015). The trial has been registered with ClinicalTrials.gov (NCT02589535). We adhered to the SPIRIT statement (Additional file 1).

\section{Study design}

Each day, the anesthesiologist in the operating room and the on-call anesthesiologist will alert the principal investigator to potential eligible patients. Participants included in the trial will be divided into two groups:

- Group C: Postoperative non-septic patients in an emergency surgical ward (control group)

Table 1 Eligibility criteria

\begin{tabular}{|c|c|}
\hline Inclusion criteria & Exclusion criteria \\
\hline \multirow[t]{5}{*}{$\begin{array}{l}\text { Caucasian } \\
\text { Over } 18 \text { years of age }\end{array}$} & $\begin{array}{l}\text { When it is impossible to collect blood } \\
\text { samples (organizational reasons or } \\
\text { because of emergencies regarding the } \\
\text { health of the patient) }\end{array}$ \\
\hline & Pregnant patients \\
\hline & Organ transplantation \\
\hline & Palliative care \\
\hline & Metastatic cancer patients \\
\hline
\end{tabular}


- Group S: Postoperative septic shock patients in an ICU

Using a computer-generated sequence of numbers, patients in group $\mathrm{S}$ will be randomly assigned to receive either conventional therapy for septic shock alone (CT) as per the Surviving Sepsis Campaign guidelines (S1) or standard therapy plus extracorporeal hemoperfusion therapy (HCT) with polymyxin B-immobilized polystyrene-derived fibers to remove endotoxins from the blood (S2) [21]. Healthy volunteers (group H) will be recruited from among staff members of the University Hospital Foggia (Figs. 1 and 2).

\section{Blood sampling}

PB samples will be collected in sterile evacuated blood collection tubes with anticoagulant ethylenediaminetetraacetic acid (EDTA; $3 \mathrm{ml}$ ) at the following time points:

- preoperatively (T0), at $24 \mathrm{~h}$ (T1), $72 \mathrm{~h}$ (T2), 7 (T3), and 10 (T4) postoperative days in groups $\mathrm{S}$ and $\mathrm{C}$

- T0 in group H

The absolute numbers of leukocytes and lymphocytes in PB will be determined at the same time with an automatic cell counter (Cell-Dyn 3500, Abbott Diagnostics, Santa Clara, CA, USA). Peripheral whole blood samples $(100 \mu \mathrm{l})$ will be used for fluorescence-activated cell sorting (FACS) analysis, and the plasma samples will be collected and stored at $-80{ }^{\circ} \mathrm{C}$.

Biochemical tests will be determined daily, according to the routine procedure in the surgical ward and ICU, and performed in the laboratories at University Hospital Foggia, according to the institutional guidelines.

Demographic, anamnestic, clinical, and laboratory data will be recorded.

\section{Flow cytometry}

The samples of whole blood $(100 \mu \mathrm{l})$ will be stained within $1 \mathrm{~h}$ from taking the blood sample. To analyze the viability of the cells, they will be stained with 7aminoactinomycin D (7-AAD), which will bind to the DNA of cells that are undergoing or have undergone apoptosis (Stem Kit ${ }^{\mathrm{Tm}}$ Beckman Coulter, Brea, CA, USA). The cell surface staining will be performed by adding the following fluorochrome-labeled monoclonal antibody reagents: fluorescein isothiocyanate (FITC)-conjugated anti-CD34 (Beckman Coulter, Brea, CA, USA) and phycoerythrin (PE)-conjugated anti-CD133 (Miltenyi Biotech, USA). Staining will be performed according to the manufacturer's guidelines.

Cells will be fixed and permeabilized using the BD Intrasure kit (Becton Dickinson, Franklin Lakes, NJ, USA) and intracellular staining of HIF-1 will be performed using HIF1 alpha (Alexa Fluor 647 anti-human HIF-1 $\alpha$ Antibody, BioLegend Inc., CA, USA) following the manufacturer's instructions. The samples will be resuspended in phosphatebuffered saline and analyzed with a FACS Caliber flow cytometer (Becton Dickinson, Franklin Lakes, NJ, USA) and FCS3 software. Cell will be acquired with a four-parameter flow cytometry method (CD34 FITC/CD133 PE/CD45 PerCP/ HIF-1 ACP staining, side, and forward angle light scatter). The flow cytometer will be calibrated every $24 \mathrm{~h}$ and quality controls performed according to the UK National External Quality Assessment Service protocol. The number of CD34/CD133/HIF-1 cells in PB will be calculated as the count of absolute lymphocytes times the percentage (\%) of gated CD34/CD133 positive cells, and expressed as absolute number of cells per $1 \mu \mathrm{l} \mathrm{PB}$.

\section{Enzyme-linked immunosorbent assay}

The plasma concentration of SDF-1a will be calculated by the enzyme-linked immunosorbent assay kit (SDF-1a

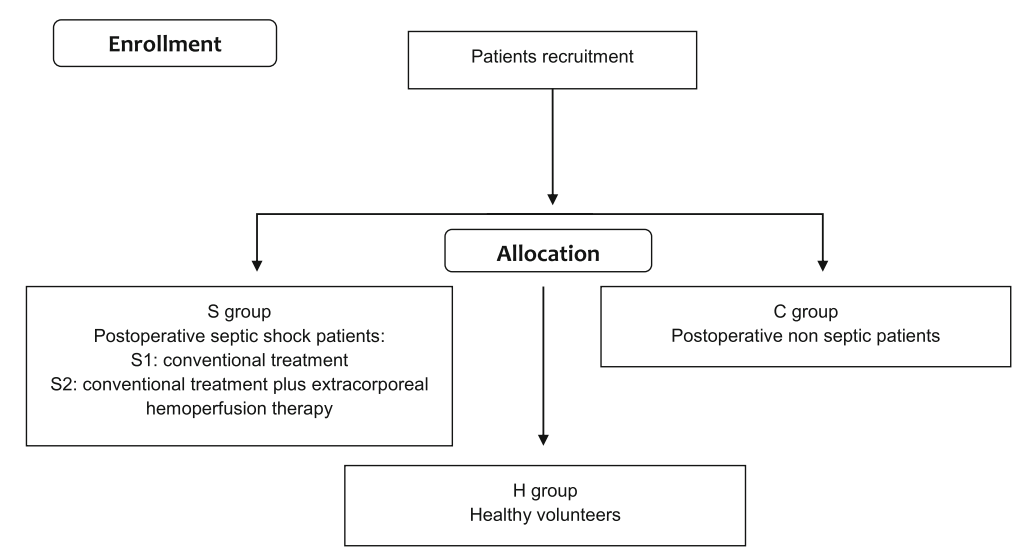

Fig. 1 Work flow for the study. After recruitment, the participants will be allocated into one of two groups: postoperative septic patients in an intensive care unit (group S) or postoperative non-septic patients in an emergency surgical ward (group C). Healthy volunteers (group H) will be recruited from among staff members of University Hospital Foggia 


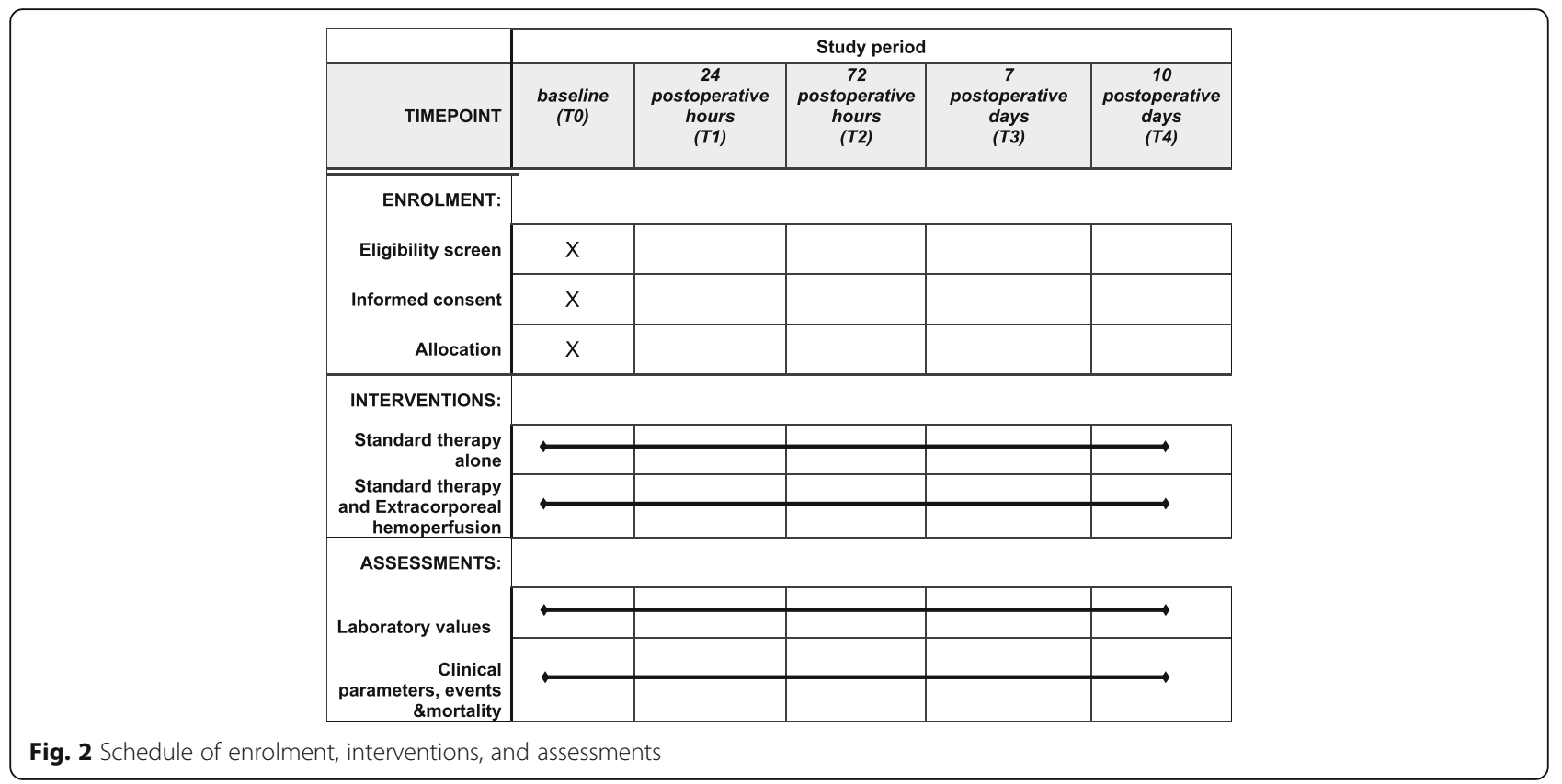

human ELISA kit, Abcam, Italy) according to the manufacturer's instructions.

\section{Statistical analysis}

The power analysis suggested that a sample size of 30 patients per group is required to detect a higher percentage of total circulating EPCs (CD133+/CD34+ cells as a percentage of all myelomonocytic cells) in septic patients vs ICU controls (assuming $\alpha=.05$ and power $=.95$ ) [22]. A sample size of three patients per group is required to detect higher SDF-1 levels in the septic vs control groups (assuming $\alpha=$ .05 and power $=.95)[10]$. This number is increased to 33 per group to allow for a $20 \%$ drop-out rate.

The normality of the distribution will be assessed by the Shapiro-Wilkinson test. If the data are normally distributed, they will be expressed as mean ( \pm standard deviation). The data will be analyzed using the repeated measurements analysis of variance. Differences between the groups at each time point will be examined post hoc using an independent sample $t$ test. A paired sample $t$ test will be used to detect changes within the groups. The level of statistical significance was chosen as $P<$ .05. The statistical analysis will be performed with the Statistical Package for the Social Sciences (SPSS Inc., Chicago, IL) version 15.0 for Windows.

\section{Discussion}

The proposed study is a prospective observational clinical trial designed to investigate in septic postoperative abdominal surgical patients: (a) levels of circulating stem cells, HIF-1, and SDF-1a; (b) the interrelationship among stem cells, HIF-1, and SDF-1a; and (c) the correlation of those factors with outcomes for septic postoperative abdominal surgical patients treated with CT alone or with HCT. The rationale is that a deep and integrated molecular understanding of sepsis at the system level will indicate which molecular processes need to be regulated to recover the innate immunity homeostasis.

A potential limitation is that blood samples will be not collected in those patients operated on as an emergency over night or when the laboratory is closed, since the HIF-1 analysis requires immediate collection-to-storage times of fresh blood samples [23].

Understanding the function of EPCs in sepsis and sepsis-related organ dysfunction may provide innovative diagnostic and therapeutic approaches for this devastating syndrome.

\section{Trial status}

Patient recruitment is currently being undertaken.

\section{Additional file}

Additional file 1: SPIRIT checklist (DOC $120 \mathrm{~kb}$ )

\section{Abbreviations}

BM: Bone marrow; $C T$ : Conventional therapy alone; EPC: Endothelial progenitor cell; FACS: Fluorescence-activated cell sorting; HCT: Conventional therapy plus extracorporeal hemoperfusion therapy; HIF-1: Hypoxia inducible factor 1; ICU: Intensive care unit; PB: Peripheral blood; SDF-1a: Stromal-cellderived factor $1 \mathrm{a}$

\section{Availability of data and materials}

The datasets used and analyzed during the current study are available from the corresponding author on reasonable request. 


\section{Authors' contributions}

AC conceived and designed the study, carried out the flow cytometry, collected and analyzed the data, coordinated the study, and wrote the manuscript. LM monitored the study with the ethics committee. SA, RV, and GF collected data. FM carried out the enzyme-linked immunosorbent assay. KM coordinated the study. LT monitored the study. GC revised the manuscript. All authors read and approved the final manuscript.

\section{Consent for publication}

Not applicable.

\section{Competing interests}

The authors declare that they have no competing interests.

\section{Publisher's Note}

Springer Nature remains neutral with regard to jurisdictional claims in published maps and institutional affiliations.

Received: 3 December 2017 Accepted: 16 February 2018

Published online: 12 March 2018

\section{References}

1. Vincent J, Rello J, Marshall J, Silva E, Anzueto A, Martin CD, et al. International study of the prevalence and outcomes of infection in intensive care units. JAMA. 2009:302:2323-9.

2. De Waele J, Lipman J, Sakr Y, Marshall JC, Vanhems P, Barrera Groba C, et al. Abdominal infections in the intensive care unit: characteristics, treatment and determinants of outcome. BMC Infect Dis. 2014;14:420.

3. Lopez N, Kobayashi L, Coimbra R. A comprehensive review of abdominal infections. World J Emerg Surg. 2011;6:7

4. Fink MP, Cotoia A, Beer-Stolz D, Liu S, Sappington PL, Delude RL. Chapter 12. Epithelial barrier dysfunction as a mechanism in the pathogenesis of multiple organ dysfunction. In: Sepsis and non-infectious systemic inflammation: from biology to critical care. Germany: Wiley-VCH Verlag GmbH \& Co. KGaA; 2009. p. 279-97. https://doi.org/10.1002/9783527626151. ch12.

5. Lepore A, D'Antini D, Raimondo P, Mirabella L, Pennisi L, Carrillo G, et al. Acute abdomen as a consequence of an unusual suicide attempt: intraabdominal injection of sulfuric acid. Int Med Case Rep J. 2016;9:353-6.

6. De Ruiter J, Weel J, Manusama E, Kingma WP, Van Der Voort PHJ. The epidemiology of intra-abdominal flora in critically ill patients with secondary and tertiary abdominal sepsis. Infection. 2009;37:522-7.

7. Hotchkiss R, Karl I. The pathophysiology and treatment of sepsis. N Engl J Med. 2003;348:138-50.

8. Sakr Y, Dubois MJ, De Backer D, Creteur J, Vincent JL. Persistent microcirculatory alterations are associated with organ failure and death in patients with septic shock. Crit Care Med. 2004;32:1825-31.

9. Mutunga M, Fulton B, Bullock R, Batchelor A, Gascoigne A, Gillespie Jl, et al. Circulating endothelial cells in patients with septic shock. Am J Respir Crit Care Med. 2001;163:195-200

10. Patschan SA, Patschan D, Temme J, Korsten P, Wessels JT, Koziolek M, et al Endothelial progenitor cells (EPC) in sepsis with acute renal dysfunction (ARD). Crit Care. 2011;15:R94. BioMed Central Ltd

11. Goligorsky MS. Endothelial progenitors in sepsis: vox clamantis in deserto? Crit Care. 2011;15:142.

12. Lemoli RM, Catani L, Talarico S, Loggi E, Gramenzi A, Baccarani U, et al. Mobilization of bone marrow-derived hematopoietic and endothelial stem cells after orthotopic liver transplantation and liver resection. Stem Cells. 2006:24:2817-25.

13. Ritz U, Spies V, Mehling I, Gruszka D, Rommens PM, Hofmann A Mobilization of $\mathrm{CD}_{3} 4^{+}$-progenitor cells in patients with severe trauma. PLoS One. 2014;9(8):e106165. https://doi.org/10.1371/journal.pone.0106165.

14. Cotoia A, Cinnella G, Grasso S, Fede NR, Pugliese PL, Massenzio F, et al. Mobilization of haematopoietic stem cells CD34+ in patients undergoing elective lung resection: observational pilot study. Arch Med. 2015:8:1.

15. Cribbs SK, Sutcliffe DJ, Taylor WR, Rojas M, Easley KA, Tang L, et al. Circulating endothelial progenitor cells inversely associate with organ dysfunction in sepsis. Intensive Care Med. 2012;38:429-36.

16. Ni G, Liu W, Huang X, Zhu S, Yue X, Chen Z, et al. Increased levels of circulating SDF-1a and CD34 ${ }^{+}$CXCR4 ${ }^{+}$cells in patients with moyamoya disease. Eur J Neurol. 2011;18:1304-9.
17. Singer M, Deutschman CS, Seymour CW, Shankar-Hari M, Annane D, Bauer $M$, et al. The third international consensus definitions for sepsis and septic shock (Sepsis-3). JAMA. 2016;315:801.

18. World Medical Association. World Medical Association Declaration of Helsinki. JAMA. 2013;310(20):2191.

19. Rafat N, Hanusch C, Brinkkoetter PT, Schulte J, Brade J, Zijlstra JG, et al. Increased circulating endothelial progenitor cells in septic patients: correlation with survival. Crit Care Med. 2007;35:1677-84.

20. International Conference on Harmonisation of technical requirements for registration of pharmaceuticals for human use. ICH harmonized tripartite guideline: Guideline for Good Clinical Practice. International Conference on Harmonisation of technical requirements for registration of pharmaceuticals for human use. J Postgrad Med. 2001;47(1):45-50.

21. Rhodes A, Evans LE, Alhazzani W, Levy MM, Antonelli M, Ferrer R, et al. Surviving sepsis campaign. Intensive Care Med. 2017:43(3):304-77.

23. Jiang BH, Semenza GL, Bauer C, Marti HH. Hypoxia-inducible factor 1 levels vary exponentially over a physiologically relevant range of $\mathrm{O} 2$ tension. Am J Phys. 1996;271:C1172-80.

22. Council for International Organizations of Medical Sciences. International ethical guidelines for biomedical research involving human subjects. Bull Med Ethics. 2002;182:17-23.

\section{Submit your next manuscript to BioMed Central and we will help you at every step:}

- We accept pre-submission inquiries

- Our selector tool helps you to find the most relevant journal

- We provide round the clock customer support

- Convenient online submission

- Thorough peer review

- Inclusion in PubMed and all major indexing services

- Maximum visibility for your research

Submit your manuscript at www.biomedcentral.com/submit
Biomed Central 